\title{
Educação e Sociedade
}

Érika Dias a

Fátima Cunha Ferreira Pinto ${ }^{b}$

A educação é, desde a sua gênese, objetivos e funções, um fenômeno social, estando relacionada ao contexto político, econômico, científico e cultural de uma determinada sociedade. $\mathrm{O}$ ato de educar é um processo constante na história de todas as sociedades, não é o mesmo em todos os tempos e lugares, e é, em sua essência, um processo social. Além disso, educação e sociedade se correlacionam porque a primeira exerce forte influência nas transformações ocorridas no âmago da segunda.

A partir dessa concepção, pode-se deduzir que, embora a educação seja um processo constante na história de todas as sociedades, o processo educativo não é o mesmo em todos os tempos e em todos os lugares, e se acha vinculado ao projeto de cidadania e de sociedade que se quer ver emergir por meio desse mesmo processo.

A educação é, portanto, um processo social que se enquadra numa certa concepção de mundo, concepção esta que estabelece os fins a serem atingidos pelo processo educativo em concordância com as ideias dominantes numa dada sociedade. A educação não pode ser entendida de maneira fragmentada, ou como uma abstração válida para qualquer tempo e lugar, mas, sim, como uma prática social, situada historicamente, numa determinada realidade.

Posto isso, o número 104 da revista Ensaio: Avaliação e Políticas Públicas em Educação apresenta aos seus leitores uma variada gama de artigos que discutem temas e objetos, os quais envolvem o fenômeno educativo e o meio social onde esse fenômeno ocorre.

As pesquisas e os ensaios aqui publicados abordam a qualidade de ensino, a inovação tecnológica, a educação ambiental, a identidade social, as políticas de ação afirmativa, o racismo e também a educação parental.

\footnotetext{
a Fundação Cesgranrio, Rio de Janeiro, RJ, Brasil - Universidade Nova de Lisboa, Lisboa, Portugal Organização das Nações Unidas para a Educação, a Ciência e a Cultura, Brasília, DF, Brasil.

b Fundação Cesgranrio, Rio de Janeiro, RJ - Academia Brasileira de Educação, Rio de Janeiro, RJ Academia Fluminense de Letras, Niterói, RJ, Brasil.
} 
Partimos do pressuposto de que a educação exerce forte influência nas transformações da sociedade. A nosso ver, a educação reforça a capacidade crítica do indivíduo e atesta o grau de desenvolvimento de uma sociedade. Quanto mais desenvolvida ela for, mais facilmente se compreenderá o papel da educação. Também é lícito referir que, em virtude de uma maior capacidade de análise que os seus cidadãos têm, maior será a transmissão do conhecimento, maior o nível do debate e da consciência com os deveres e as responsabilidades na defesa e na promoção dos direitos humanos e sociais (PINTO; DIAS, 2018).

Neste número, contamos com artigos oriundos da Europa e da África, além das pesquisas de variadas regiões do Brasil. Os artigos abordam diferentes temáticas, temáticas estas que perpassam pelo Ensino Superior, pelo Ensino Fundamental e Médio, pelas tecnologias da informação e da comunicação, utilizadas por alunos e professores, pela qualidade de ensino em centros educativos, pela educação ambiental, pelo desempenho dos institutos federais no Brasil e pelas inovações no ensino secundário na Rússia.

Sempre foi importante para a revista Ensaio publicar artigos sobre pesquisas, vivências e experiências de outros espaços educacionais - fora das nossas fronteiras -, para que as realidades dos outros contribuíssem para uma melhor percepção da nossa sociedade e para uma melhor compreensão do nosso contexto educacional.

Assim, escolhemos iniciar o número 104 com uma pesquisa da África do Sul, intitulada "Unboxing 'born-frees': Freedom to choose identities". Trata-se de uma investigação que analisou como estudantes "nascidos livres", isto é, vinte anos após o fim do apartheid, compreendiam suas identidades. A pesquisa mostrou que alguns alunos expressavam otimismo pela liberdade, mas outros se sentiam constrangidos pela herança persistente do regime de segregação racial. $\mathrm{O}$ artigo se correlaciona com a obra de Paulo Freire, quando, na primeira edição, em 1996, no livro intitulado "Pedagogia da Autonomia: saberes necessários à prática Educativa", fez uma reflexão acerca da educação, do preconceito e da democracia. Para Paulo Freire, a rejeição de qualquer forma de discriminação faz parte do que é certo. "A prática preconceituosa de raça, de classe, de gênero ofende a substantividade do ser humano e nega radicalmente a democracia" (FREIRE, 2011, p. 17). A pesquisa demonstra que parte dos alunos, que não viveu o regime separatista, e que vive atualmente num país democrático, convive com os legados físicos deste mesmo regime - como a segregação geográfica - demonstrando que esses alunos sul-africanos não são tão diferentes de outros que precisaram resistir à implementação do regime e falharam. Ivo e Ivanio Dickmann, ao analisarem a obra de Freire, referem que para o autor ninguém tem liberdade para ser livre, há uma luta permanente pela 
liberdade justamente porque não a tem (Dickmann, Dickmann, p. 28). O texto segue a mesma linha de pensamento no que tange à compreensão do aluno sobre ser livre.

Da região Sudeste do Brasil, recebemos o artigo "Como o acesso à educação desmonta o mito da democracia racial", demonstra como este mito já não pode mais ser sustentado, quando tantos dados mostram a exclusão do negro nos níveis mais altos de ensino, nos postos mais altos das organizações, ou mesmo sua predominância no sistema penitenciário do país. As relações raciais no Brasil são sim discriminatórias. A negação do racismo apenas perpetua as injustiças sociais em relação aos negros no país. A educação e as políticas públicas passam a ser peça fundamental para a diminuição das desigualdades sociais, econômicas e regionais, indispensáveis para um verdadeiro Estado de direito democrático e social. Nesse sentido, as políticas afirmativas adquirem relevância, tendo em vista a ideia de igualdade de oportunidades e de sua respectiva concepção de mérito, não se mostrar suficiente para a redução da desigualdade. A Educação, mais uma vez, surge como ferramenta de transformação social (BORDIEU, 1987). A educação modifica a realidade social.

Ainda no âmbito do Ensino Superior, publicamos uma pesquisa oriunda da região Centro-Oeste do Brasil, intitulada "Jovens universitários em silêncio no mundo das informações: casos de liberação", que investigou estratégias de superação da lógica de violência, exclusão e silêncio, aos quais estão submetidos os jovens universitários. A investigação concluiu que os momentos de superação destes indivíduos, que entram nas universidades muito jovens, são potenciais estratégias educacionais transformadoras, que levam do discurso à prática, da opressão à esperança.

Da Espanha chega-nos um artigo intitulado "Las Educadoras y Educadores Sociales ante la Sociedad, red", com os resultados de uma investigação sobre o grau de competência digital autopercebida pelos futuros Educadores Sociais, a fim de identificar o quê os educadores conhecem, se sabem manejar as ferramentas tecnológicas, qual a atitude que os educadores têm em relação às TICs, objetivando compreender o desenvolvimento profissional dos educadores e educadoras numa sociedade digital, cada vez mais em rede.

Do Rio Grande do Sul, apresentamos os resultados de uma pesquisa intitulada "Percursos escolares de estudantes do ensino médio de escolas públicas do município de São Leopoldo, RS: desempenho escolar, perfil e características". A pesquisa analisou os percursos escolares de estudantes do ensino médio, por meio da identificação de perfis que interferem nas desigualdades escolares, especialmente de fluxo escolar, levando à aprovação, à reprovação e ao abandono escolar. Por meio de um estudo quantitativo, a pesquisa identificou evidências que permitem afirmar que as diferenças de perfis associadas às características dos estudantes de 
escolas públicas relacionam-se com a produção de desigualdades educacionais e sinalizam, além disso, situações de vulnerabilidades sociais que se reproduzem nos espaços escolares. O estudo notou que, nas escolas públicas pesquisadas, há diferenças singulares entre os estudantes do ensino médio diurno e noturno.

De um contexto educacional diferente do nosso, oriundo da Espanha, publicamos um artigo intitulado "Procesos de mejora en los centros educativos: ejemplificación de tres campos de análisis e innovación docente". Pesquisadores de Madri fizeram um estudo relevante no âmbito do ensino fundamental, cujos resultados contribuem para o debate pedagógico internacional. Por meio de uma pesquisa bibliográfica, analisaram a questão da qualidade do ensino em centros educativos na Espanha. Concluíram que, para que a tão almejada eficácia escolar seja alcançada, é preciso levar em conta o contexto socioeconômico das famílias, o momento histórico, a realidade política, os processos culturais, o professor, as características dos alunos, entre outros fatores. Para os pesquisadores, as medidas para melhorar a qualidade do ensino devem ser combinadas, a partir de aspectos econômicos, políticos e socioeducativos, de forma clara. Em segundo lugar, é preciso favorecer as escolas que são permeáveis à participação real das famílias, flexívies e abertas à mudança e melhoria dos currículos e da didática. E, por último, deve ser promovida uma formação inicial e permante de professores de qualidade, permitindo-lhes compreender a magnitude existente entre o social, a aprendizagem e a emoção. Professores que compreendam a importância de gerar processos educativos integrais, baseados na interdependência entre o cognitivo e o emocional, entre o analítico e o criativo, entre o intelectual e o lúdico.

Da Rússia, chega-nos um texto que reflete sobre a resistência de professores a inovação tecnológica e mostra ao leitor como essa inovação é relevante para a modernização e melhoria da qualidade do ensino secundário naquele país. $\mathrm{O}$ artigo intitula-se "Major factors of teachers" resistance to innovations" e a abordagem ampla da pesquisa permitiu identificar fatores sociais, psicológicos e profissionais que predeterminavam a resistência dos professores às mudanças. $\mathrm{O}$ estudo conclui que a modernização no treinamento dos professores, uma contínua formação, contribuiu significativamente para acelerar o processo e aumentar a eficiência pedagógica.

Da Universidade Católica de Brasília, publicamos o artigo intitulado "O uso de indicadores para avaliação qualitativa de projetos educativos socioambientais: a gestão participativa no ambiente escolar". O artigo discutiu os novos paradigmas educacionais, voltados para o desenvolvimento sustentável, a fim de se construir um novo modelo de escola, a partir da interação mais eficaz de todos os envolvidos 
no processo educacional - alunos, família e sociedade. Os autores concluem que é imperativo trabalhar também a interdisciplinaridade junto com o planejamento e o desenvolvimento dos sistemas educativos. No entendimento dos autores, seria preciso que os formuladores e executores de políticas públicas em educação tivessem consciência de uma nova concepção de educação que incluísse uma visão mais ampla do planeta, cujos recursos, fundamentais para a vida precisavam ser administrados com ética e responsabilidade coletiva.

Do Nordeste, apresentamos o artigo intitulado "O que mudou no desempenho educacional dos Institutos Federais do Brasil?". A pesquisa investigou os diferentes níveis de proficiência obtidos por esses institutos no Enem e concluiu que o desempenho foi positivo quando os institutos foram avaliados como redes de ensino, bem como, quando foram avaliados em contextos que preservavam as características individuais de suas unidades.

Na seção Página Aberta, publicamos um artigo oriundo de Portugal, intitulado "O valor das práticas de educação parental: visão dos profissionais". Pesquisa na qual os autores procuraram demonstrar a relevância da educação parental num contexto de redução de disponibilidade do apoio comunitário e da família tradicional, antes alargada. Procuraram entender como esses profissionais são um apoio às famílias e apresentam-se como uma valiosa medida de auxílio às competências parentais que têm as necessidades de pais e filhos no centro das suas atuações. A amostra do estudo foi constituída por 180 profissionais, que atualmente trabalham em Portugal, na área da educação parental. Os resultados mostraram que a formação em nível avançado se tornou uma componente relevante na valorização das práticas de educação parental por parte dos profissionais, o que implica atualmente a necessidade de uma resposta das instituições de ensino superior com cursos de formação profissional para tal área.

As pesquisas que ora publicamos, com uma grande variedade temática, demonstram que a educação continua a ser uma ferramenta para a transformação das mais distintas sociedades. A leitura dos artigos, oriundos do Brasil, Espanha, Portugal e Rússia, fará o leitor refletir sobre a formação de professores, o investimento em inovação tecnológica, o respeito às diferenças, a luta contra o preconceito, a relevância dos profissionais da educação - sejam eles professor, pesquisador ou profissional da educação parental -, e sobre a qualidade de ensino que queremos nas nossas escolas e universidades. Concordamos com Ana Ivenicki quando refere que,

A ressignificação das políticas na vida das escolas e em outras instituições educacionais passa a ser percebida como aquela em 
que os potenciais de todos são incentivados, focalizando os atores educacionais como protagonistas de um movimento que desafie preconceitos, assédios e quaisquer formas de violência, racismos, sexismos, bullying e outros abusos, de modo a que se contribua para a formação de identidades comprometidas com direitos humanos, com a pluralidade e com valores democráticos de cidadania. (IVENICKI, 2019, p. 2)

A continuação de políticas públicas voltadas a escolas, grupos vulneráveis, no Brasil e fora do Brasil, é necessária e precisa tornar-se realidade na pluralidade institucional, em nível micro e macro, a fim de que a educação possa cumprir o seu papel de agente transformador da sociedade. 


\section{REFERÊNCIAS}

BORDIEU, P. Coisas ditas. São Paulo: Brasiliense, 1987.

DICKMANN, Ivo; DICKMANN, Ivanio. Primeiras palavras em Paulo Freire. $3^{\text {a }}$ ed., Chapecó: Editora Livrologia, 2019.

FREIRE, P. Pedagogia da autonomia: saberes necessários à prática educativa. 43. ed., São Paulo: Paz e Terra, 2011.

IVENICKI, A. A escola e seus desafios na contemporaneidade. Ensaio: Avaliação e Políticas Públicas em Educação, Rio de Janeiro, v. 27, n. 102, p. 1-8, mar. 2019 . https://doi.org/10.1590/s0104-40362018002700001

PINTO, F. C. F.; DIAS, E. Educação e pesquisa. Ensaio: Avaliação e Políticas Públicas em Educação, Rio de Janeiro, v. 26, n. 100, p. 505-8, jul. 2018. https://doi.org/10.1590/s0104-40362018002610001

\section{Informação das autoras}

Érika Dias: Doutora em História Moderna pela Universidade Nova de Lisboa (UNL). Editora da revista Ensaio: avaliação e políticas públicas em Educação; pesquisadora correspondente do Centro de História de Humanidades da UNL e consultora da Unesco Brasil no âmbito do Projeto Resgate Barão do Rio Branco. Contato: erikadias@cesgranrio.org.br

(iD) https://orcid.org/0000-0002-5608-646X

Fátima Cunha Ferreira Pinto: Doutora em Filosofia, com Pós-Doutorado pela Universidad Nacional de Educación a Distância. Editora da revista Ensaio: avaliação e políticas públicas em Educação; assessora Especial da Presidência e dos Projetos Especiais da Fundação Cesgranrio; membro da Academia Brasileira de Educação (ABE) e da Academia Fluminense de Letras (AFL). Contato: fatimacunha@cesgranrio.org.br

(iD) https://orcid.org/0000-0002-4461-8414 